\title{
Irritable bowel syndrome among High School Students, Bagdad, Iraq, 2017-2018
}

\author{
Hanaa F. Hazaa* \\ Faris H. Lami**
}

\author{
$\mathrm{MBChB}$ \\ MBChB, PhD, FFPH
}

\begin{abstract}
:
Background: Irritable Bowel Syndrome (IBS) is a common chronic functional gastrointestinal disorder characterized by abdominal pain or discomfort and alteration in bowel habits. It is more common among adolescents and young age groups.

Objectives: to estimate the prevalence and identify potential determinants of IBS among high school students in Baghdad, Iraq, 2017.

Methods: This cross-sectional study was conducted by using multi-staging cluster probability sampling technique. All students in the sixth grade were considered eligible. Students with "red flag" symptoms were excluded. Rome III criteria questionnaire of IBS was considered to define IBS. A self-administered questionnaire used to compile socio-demographics, personal habits and certain potential determinants. IBS was further classified as mixed type (M-IBS), diarrhea predominant type (D-IBS) and constipation predominant type (C-IBS).

Result: Among 657 eligible high school students, 592 (90.1\%) were enrolled. The prevalence of IBS was $29.7 \%$ (95\% C.I: $29.4-30.1 \%$ ). The most common type of IBS was M-IBS (42.6\%) followed by D-IBS $(33.5 \%)$. Binary and logistic regression analyses revealed the following significant factors: exposure to stressful life event (OR: 3.93; 95\% CI: $2.64-4.85$ ), food hypersensitivity (OR: $2.89 ; 95 \%$ CI: $1.59-3.27$ ), chronic diseases (OR: 2.22; 95\% CI: $1.24-3.95$ ), family history of IBS (OR: 2.04; 95\% CI: $1.30-3.01$ ) and female sex (OR: 1.84 ; $95 \%$ CI: $1.25-2.73)$. C-IBS was significantly more common among females $(\mathrm{P}=0.02)$

Conclusion: IBS is a common health problem among high school students. Among the hereditary, environmental and psycho-social factors, stress was the most important determinant.

Keyword: Irritable Bowel Syndrome, High School students, Prevalence, Risk factors, Iraq.
\end{abstract}

\section{Introduction:}

Irritable bowel syndrome (IBS) is a chronic disease of large intestine causing abdominal pain and change in bowel habits in the absence of a specific organic pathology [1]. The chronic and relapsing nature of IBS has proposed diagnostic criteria which based on the occurrence rate of symptoms and their duration [2]. Altered gastrointestinal motility, visceral hypersensitivity, post-infectious reactivity, food sensitivity, dietary intakes, and intestinal inflammation have been contributed to the pathogenesis of IBS [3]. IBS is a multifactorial disorder though its causes and risk factors remain unclear. But, stress is the main factor that has marked impact on intestinal motility, sensitivity and stimulation of colon spasms among IBS patients [4]. Globally, IBS is prevalent in both developed and developing countries. It affected about $10-20 \%$ of people, with mean prevalence range from $1.1 \%$ in France and Iran to $35.5 \%$ in Mexico [5]. IBS occurs in all age groups and affects even children, but it is more prevalent in those under 25years old and then modestly declines with increasing age [6]. This may be related to the combined effects of physiological changes in adolescence period and the psychological factors related to study, work or family [7].

*Al-Resafa Directorate of Health, Iraq Ministry of Health/Email: hanaa.hazaa@gmail.com **Department of Community and Family Medicine, College of Medicine, University of Baghdad
IBS is considered as the second major factor associated with loss of productivity and work absenteeism. Some studies estimated that the total annual cost of IBS is up to $\$ 30$ billion; $\$ 20$ billion as a direct cost related to the disease diagnosis, management and treatment in addition to $\$ 10$ billion in term of indirect cost defined as productivity cost and work absenteeism [8]. However; in term of loss of productivity, patients with IBS missed annually about three times as many days from school or work as people without IBS [9]. Although IBS remains a common disorder with high prevalence in adolescents and young age groups with negative impacts on patients' school, partner's life and society. [10], there is little information about IBS prevalence and risk factors in Arab countries, including Iraq. The objective of this study was to estimate the prevalence and identify the determinants of IBS among high school students in Baghdad, Iraq, 2017.

\section{Subjects and Method:}

Design and Setting: This is a cross-sectional study that was conducted on a sample of high schools students in Bagdad, Iraq. Sampling: A multi-stage cluster sample technique were be applied to select 12 high schools from a list of all high schools in Bagdad which obtained from the Ministry of Education. Then to choose students entered the study. Study population: students of the sixth grade 
of the selected schools were initially considered eligible. Students with history of confirmed diagnosis of GI disease other than IBS or surgery for GI diseases were excluded. Students with alarming "red flag" symptoms: blood in stool, unexplained weight loss in last three month, bloody vomiting, fever, nocturnal symptoms, family history of colon cancer and inflammatory bowel disease or celiac disease were also excluded.[11] Data collection: Two self-administrated questionnaires were adopted. The first questionnaire was for socio-demographics characteristics; age, gender, monthly family income (classified as: low <400\$, medium 400-1,200\$ and high >1,200\$) and current parents' status, personal habits (smoking, daily sleeping hours and daily meals), medical history of chronic diseases (Diabetes, Asthma, Migraine, Hypertension ...etc.), regular medication (any medication taken on regular basis in the last six month), food hypersensitivity (allergic reaction to certain type of food causing digestive, skin, respiratory or eye manifestation), history of stressful life events (events which predict stress according to Holmes and Rahe Stress Scale; including Death of one of close relative, continuous family or economic problems, migration, causes related to study or school and others)[12] and family history of IBS[ family history of first degree relative]. The second was Rome III diagnostic criteria questionnaire, which is a validated selfadministrated questionnaire that consists of ten questions, each question can be answered according to a scale describing the frequency of each symptom. According to Rome III criteria, IBS is defined as a frequent abdominal pain or discomfort for at least three days per month in the last three months since six month ago, associated with two or more of the following: a) relief with defecation, 2) change in frequency of stools, 3) change in stool appearance [13]. The diagnosis of IBS was made by using the Rome III criteria as long as the patient does not have any of red flag symptoms. Thereafter; the patients were classified as having constipation predominant (IBS-C); if they had hard or lumpy stools with no loose or mushy watery stools, or diarrhea predominant (IBS-D); if they had loose or mushy watery stools with no hard or lumpy stools and mixed subtypes (IBS-M); if they had loose or mushy stools with hard or lumpy stools in the past three months [14]. In our study we depended an Arabic version questionnaire which had used previously in other Arabic studies [15, 16] after we assessed and validated it by specialists in department of Gastroenterology. Ethical and Official Approvals: Official approval was granted from the Directorates of Education in Baghdad/ Iraq Ministry of Education. Ethical approval was obtained from the Medical Research Ethics Committee/ Iraq Ministry of Health and the Scientific Research Committee in the College of Medicine, University of Baghdad. The participants were verbally informed about the objectives of study and they were not obligate to take part in the study. All names were deleted after replacing them with identification number. Data was kept confidential and used exclusively for the sake of this study.

Statistical analysis: Statistical Package for Social Sciences (SPSS) program, version 23 was used for data entry and analysis. The prevalence (and its $95 \%$ confidence interval) of IBS among high school students was calculated. Chi square and fisher's exact probability test were applied to test association of qualitative and categorical variables with IBS. Logistic regression analysis was used to identify the significant, independent and un-confounded risk factors. In the model, IBS was considered the dependent variable and all the variables that were found significant in the binary analysis were included as the independent variables.

\section{Results:}

Among the 657 interviewees, 65 (9.9\%) were excluded because of alarm features or non-response, leaving a total of 592 eligible participants. The mean age $( \pm \mathrm{SD})$ of the students was $18.05( \pm 1.28)$ years, with almost equal proportions of males and females. Most of the students lived with their parents (87.2\%) and $10.5 \%$ had one or both parents deceased. About half of students had average monthly family income of $400-1200 \$$. We found that $34.1 \%$ of students were currently smokers; $70.9 \%$ were sleeping less than eight hours per day and $47.6 \%$ had irregular meals. The prevalence of IBS among high school students in Baghdad was $29.7 \%$ (176) (95\% C.I: 29.4-30.1\%). In table 1, the study sample was cross classified by IBS and certain socio-demographic characteristics and personal habits. The highest prevalence of IBS was among students aged 17-19 $(30.3 \%)$ and the lowest prevalence was among students aged $>20$ years $(11.3 \%)$; still no significant association was found between age group and IBS $(\mathrm{P}=0.86)$. On the contrary, the prevalence of IBS was $35.6 \%$ (110/309) among females compared to $23.3 \%(66 / 283)$ among males; the difference was statistically significant $(\mathrm{P}<0.001)$. The female to male ratio was: $1.5: 1$. There was an increased prevalence of IBS among students who had one or both parents deceased (43.5\%) with a significant association between current parents' status and prevalence of IBS $(\mathrm{P}=0.04)$. A significant proportion of the students from low economic status (36.1\%) had IBS compared to those from middle economic status $(29.5 \%)$ and high economic status (26.8\%), but no statistical association was demonstrated between economic status and IBS $(\mathrm{P}=0.27)$. Table 1 shows the highest prevalence of IBS was seen among smokers (34.2\%), among students who were sleeping $<8 \mathrm{hr}$. /day (31.9\%), and among those who had irregular meals $(33.0 \%)$; still, there was no statistical association between smoking $(\mathrm{P}=0.091)$, daily sleeping hours $(\mathrm{P}=0.08)$ and irregular meals $(\mathrm{P}=0.10)$ with IBS. Table 2 shows that the prevalence of IBS was significantly higher among students with history of chronic disease (40.3\%) $(\mathrm{P}=0.04)$, family history of IBS $(37.6 \%)(\mathrm{P}<0.001)$, students having history of food hypersensitivity $(54.2 \%)(\mathrm{P}<0.001)$ and students with stressful life 
events $(44.6 \%) \quad(\mathrm{P}<0.001)$, but there was no significant association between history of regular medication and IBS $(\mathrm{P}=0.43)$. Logistic regression analysis was applied, and the results as demonstrated in table 3 showed that the following were the factors that significantly predict the occurrence of IBS in the study population: having stressful life event $(\mathrm{P}<0.001)$, food hypersensitivity $(\mathrm{P}<0.001)$, chronic health problem $(\mathrm{P}=0.01)$, family history of IBS $(\mathrm{P}<0.001)$ and female sex $(\mathrm{P}=0.01)$. In table 4 , we noticed that Diarrhea predominant IBS (IBS-D) constituted $33.5 \% \quad(59 / 176)$, Constipation predominant IBS (IBS-C) constituted $23.9 \%$ (42/176), and the remaining $42.6 \%$ (75/176) were of mixed type (IBS-M). The proportion of IBS-C constituted $29.4 \%$ of female IBS students compared to $14.9 \%$ among males IBS students, while the proportion of IBS-D was seen in $44.8 \%$ among males IBS students compared to $26.6 \%$ among females IBS students $(\mathrm{P}=0.02)$.

Table1: Distribution of the study group by IBS and certain demographic characteristics

\begin{tabular}{|c|c|c|c|c|c|c|c|c|}
\hline \multirow{2}{*}{$\begin{array}{l}\text { Socio-demographic } \\
\text { Variables }\end{array}$} & \multicolumn{3}{|c|}{ Total $(n=592)$} & \multicolumn{2}{|c|}{ IBS $(n=176)$} & \multicolumn{2}{|c|}{ No IBS $\quad(n=416)$} & \multirow[t]{2}{*}{ P- Value } \\
\hline & No & $\%$ & No & No & $\%$ & No & $\%$ & \\
\hline \multicolumn{9}{|l|}{ Age (Year) } \\
\hline$<17$ & 19 & 3.2 & 19 & 5 & 26.3 & 14 & 3.2 & \multirow{3}{*}{0.86} \\
\hline $17-19$ & 501 & 84.7 & 502 & 152 & 30.3 & 350 & 84.7 & \\
\hline$\geq 20$ & 72 & 12.1 & 72 & 20 & 11.3 & 52 & 72.2 & \\
\hline \multicolumn{9}{|l|}{ Sex } \\
\hline Male & 283 & 49.5 & 283 & 66 & 23.3 & 217 & 76.7 & \multirow[t]{2}{*}{$<0.001$} \\
\hline Female & 309 & 505 & 309 & 110 & 35.6 & 199 & 64.4 & \\
\hline \multicolumn{9}{|l|}{ Parents' status } \\
\hline Live together & 508 & 85.8 & 508 & 143 & 28.1 & 365 & 71.9 & \multirow{3}{*}{0.04} \\
\hline Separated & 22 & 3.7 & 22 & 6 & 27.3 & 16 & 72.7 & \\
\hline Death of one or Both & 62 & 10.5 & 62 & 27 & 43.5 & 35 & 56.5 & \\
\hline \multicolumn{9}{|l|}{ Monthly income } \\
\hline$<400 \$$ & 97 & 16.4 & 97 & 35 & 36.1 & 62 & 63.9 & \multirow{3}{*}{0.27} \\
\hline $400 \$-1,200 \$$ & 305 & 51.5 & 305 & 90 & 29.5 & 215 & 70.5 & \\
\hline$>1,200 \$$ & 190 & 32.1 & 190 & 51 & 26.8 & 139 & 73.2 & \\
\hline \multicolumn{9}{|l|}{ Smoking } \\
\hline Smoker & 202 & 34.1 & 202 & 69 & 34.2 & 133 & 65.8 & \multirow[t]{2}{*}{0.09} \\
\hline Non smoker & 390 & 65.9 & 390 & 107 & 27.4 & 283 & 72.6 & \\
\hline \multicolumn{9}{|l|}{ Sleeping hours } \\
\hline$<8$ hrs. & 420 & 7.9 & 420 & 134 & 31.9 & 286 & 68.1 & \multirow[t]{2}{*}{0.08} \\
\hline$\geq 8 \mathrm{hrs}$. & 172 & 29.1 & 172 & 42 & 24.4 & 130 & 75.6 & \\
\hline \multicolumn{9}{|l|}{ Regular meals } \\
\hline No & 382 & 47.6 & 282 & 93 & 33.0 & 189 & 67.0 & \multirow[t]{2}{*}{0.10} \\
\hline Yes & 310 & 52.4 & 310 & 83 & 26.8 & 227 & 73.2 & \\
\hline
\end{tabular}

Table 2: Distribution of the study group by certain potential risk factors

\begin{tabular}{|c|c|c|c|c|c|c|c|}
\hline \multirow[t]{2}{*}{ Variables } & \multicolumn{2}{|c|}{ Positive IBS } & \multicolumn{2}{|c|}{ Negative IBS } & \multicolumn{2}{|c|}{ Total } & \multirow[t]{2}{*}{ P-value } \\
\hline & No & $\%$ & No & $\%$ & No & $\%$ & \\
\hline \multicolumn{8}{|c|}{ Chronic health problems } \\
\hline Yes & 29 & 40.3 & 43 & 59.7 & 72 & 12.2 & \\
\hline No & 147 & 28.3 & 373 & 71.7 & 520 & 87.8 & 0.04 \\
\hline \multicolumn{8}{|c|}{ Regular medication } \\
\hline Yes & 12 & 36.4 & 21 & 63.6 & 33 & 5.6 & \\
\hline No & 164 & 29.3 & 395 & 70.7 & 559 & 94.4 & 0.43 \\
\hline \multicolumn{8}{|c|}{ Family history of IBS } \\
\hline Positive & 94 & 37.6 & 156 & 62.4 & 250 & 42.2 & \\
\hline Negative & 82 & 24.0 & 260 & 76.0 & 342 & 57.8 & $<0.001$ \\
\hline \multicolumn{8}{|c|}{ Food hypersensitivity } \\
\hline Positive & 32 & 54.2 & 27 & 45.8 & 59 & 10.0 & \\
\hline Negative & 144 & 27.0 & 389 & 73.0 & 533 & 90.0 & $<0.001$ \\
\hline \multicolumn{8}{|c|}{ Stressful life events } \\
\hline Present & 124 & 44.6 & 154 & 55.4 & 278 & 47.0 & \\
\hline Absent & 52 & 16.6 & 262 & 83.4 & 314 & 53.0 & $<0.001$ \\
\hline
\end{tabular}

Table 3: Significant risk factors of IBS as demonstrated by logistic regression analysis

\begin{tabular}{llll}
\hline \multicolumn{1}{c}{ Variables } & Odd's Ratio & $95 \%$ C.I for & P-Value \\
\hline Stressful life event & 3.928 & $2.637-4.853$ & $<0.001$ \\
\hline Food hypersensitivity & 2.894 & $1.588-3.274$ & $<0.001$ \\
\hline Chronic health problems & 2.217 & $1.244-3.950$ & \\
\hline Family history of IBS & 2.040 & $1.298-3.009$ & 0.01 \\
\hline Gender & 1.843 & $1.245-2.730$ & $<0.001$ \\
\hline
\end{tabular}


Table 4: Distribution of IBS group by IBS type and sex

\begin{tabular}{|c|c|c|c|c|c|c|c|c|c|}
\hline \multirow{4}{*}{ Sex } & \multicolumn{8}{|c|}{ IBS } & \multirow{4}{*}{$\mathrm{P}$-value } \\
\hline & \multirow{2}{*}{\multicolumn{2}{|c|}{$\begin{array}{l}\text { Cons-tipation } \\
\text { IBS }\end{array}$}} & \multirow{2}{*}{\multicolumn{2}{|c|}{$\begin{array}{l}\text { Diarrhea } \\
\text { IBS }\end{array}$}} & \multirow{2}{*}{\multicolumn{2}{|c|}{$\begin{array}{l}\text { Mixed } \\
\text { IBS }\end{array}$}} & \multirow{2}{*}{\multicolumn{2}{|c|}{ Total }} & \\
\hline & & & & & & & & & \\
\hline & No & $\%$ & No & $\%$ & No & $\%$ & No & $\%$ & \\
\hline Male & 10 & 14.9 & 30 & 44.8 & 27 & 40.3 & 67 & 38.1 & \\
\hline Female & 32 & 29.4 & 29 & 26.6 & 48 & 44.0 & 109 & 61.9 & \\
\hline Total & 42 & 23.9 & 59 & 33.5 & 75 & 42.6 & 176 & 100 & 0.02 \\
\hline
\end{tabular}

\section{Discussion:}

IBS is a common chronic gastrointestinal disorder and determining its prevalence is important for health economies, burden of disease and allocation of healthcare resources [9]. In this study, around $30 \%$ of high school students had IBS; this is very close to the reported prevalence from a study involving the general population in one governorate in Iraq [17]. The reported prevalence in this study is higher than the rates reported from Europe, Africa and many Asian countries [18, 19, and 20]. Still, it is close to the rates reported in studies from Middle Eastern countries $[16,21]$. This variation may be explained by social, environmental and genetics factors and dietary habit which differ from one geographical area to another [6]. While, many studies reported inverse relationship between age and the rate of IBS [18, 20], such association was difficult to demonstrate in this study, as the age range of the studied sample was extremely narrow. Similar finding was reported in Saudi Arabia in a study on adolescent aged 15-23 years [15]. The higher prevalence of IBS reported among females had been demonstrated by other studies $[4,5]$. In this study, females had almost twice the odds of having IBS after controlling of potential confounders. This may be related to hormonal factors, psychosocial factors and sex differences in stress response and autonomic response that may influence gastrointestinal motility and visceral hypersensitivity [22]. The study revealed a significant effect of exposure to stressful life event on prevalence of IBS, and this is concordant with other studies that demonstrated the role of psychological factors on IBS occurrence [23, 24]. The physiological changes of adolescence and inadequate experience to deal with life stresses make the students more sensitive and less resilient to family problems, financial difficulties, sexual abuse and study or work stress [7]. In Iraq, the marks achieved by the students at the end of the $12^{\text {th }}$ year is the only factor that decides the type and rank of academic studies; a factor that makes the students and their families under a considerable stress. Having food allergy was another factor associated with increased odds of having IBS. While studies conducted in Lagos [18] and Lebanon [25] revealed similar finding, another study denied such association. [26]. Food may activate an immunoreaction in the gut that induces IBS by a similar pathophysiological mechanism of atopic conditions [20]. In this study, we identified a familial role of IBS, in term of positive family history. A similar finding was reported by other studies. [26, 27]. IBS represents a complex genetic disorder which interact with several environmental factors, resulting in the disruption of intestinal function. [27] While history of chronic diseases was a significant factor for IBS, regular use of medication was found non-significant factor. The findings from other studies were controversial, as some studies found chronic diseases a significant independent risk factor of IBS [26, 28], other studies did not support such association. [21, 24]. Similarly, some studies demonstrated a significant association between regular medication intake and IBS [28, 29], another study did not find such association [30]. The role of the parents' status whether living together, separated or deceased is not clear. On univariate analysis it was statistically significant and the proportion of IBS among students with one or both deceased parents was almost double those who lived with their parents together. Yet, in logistic regression analysis this factor was found not significant. Other studies also showed uncertain results [22, 30], although, another study considered it as a risk factor and explained that on the basis of having both parents living together may entitle more emotional stability, care and support to the adolescents and better cope with life stresses. [15]. This study revealed a lack of association between the monthly family income and IBS, which is consistent with a study in Saudi Arabia [16]. Other studies demonstrated that individuals with high family income can cope better with stressful life events $[25,30]$. The three studied personal habits: smoking, irregular meals and sleeping hours were found non-significant determinants. The reviewed studies demonstrated controversial results. While some support smoking [29] as a risk factor, others did not [30, 31]. Also, irregular meals were considered significant risk factor in one study [22], while others considered it not a risk factor [21, 31]. On a similar scale, sleeping less than $8 \mathrm{hr}$./ day was considered as a significant risk factor for IBS in some studies $[23,29]$ others did not support that [24, 26, 30]. Different study methods, definitions of variables and sample sizes might be behind these variations. The mixed type was the most prevalent type of IBS and the significant association between sex and IBS type is also demonstrated by other studies. [18] [23, 30]. In this study, data were fully obtained through the self-administered questionnaire, and considering the sensitivity of adolescents that may affect their responses, misclassification can't be ruled out. Also, as this is a cross sectional study, the temporal relationship between the identified determinants and IBS can't be demonstrated with confidence; hence causal association can't be inferred. We can conclude that 
IBS is a common disorder among adolescents in Iraq particularly females. Hereditary, environmental, psychosocial factors play an important role in the conception of the disease and stress was the most important modified risk factor affecting its prevalence.

\section{Authors' Contributions:}

Dr. Hanaa F. Hazaa; Master student; Data collection, analysis and discussion

Dr. Faris H. Lami* MBChB, PhD, FFPH Supervisor

\section{References:}

1. World Gastroenterology Organization Global Guidelines. Irritable Bowel Syndrome: a Global Perspective. $\quad 2015$. www.worldgastroenterology.org./guidelines/globalguidelines. 23/9/2017.

2. Occhipiniti K. and Smith, J.W. Irritable Bowel Syndrome: A Review and Update. Clinics in colon and Rectal Surgery, 2012, 25, 46-52.

3. Qin H.Y., Cheng C.W., Tang X.D. and Bian Z.X., Impact of psychological stress on irritable bowel syndrome. World J Gasteroenterol 2014, 20(39): 14126-1413.

4. Ford, A.C.; Lacy, B.E.; Talley, N.J. Irritable Bowel Syndrome. N. Engl. J. Med. 2017, 376, 2566 257[PubMed].

5. Sperber AD, Dumitrascu D, Fukudo S, et al. The global prevalence of IBS in adults remains elusive due to the heterogeneity of studies: a Rome Foundation working team literature review. Doi: 10. 1136/guljnle. 2015-311240.

6. Lovell RM, Ford AC. Global prevalence of and risk factors for irritable bowel syndrome: A metaanalysis. Cline. Gastroenterology. Hepatic. 2012, 10(7):712-721.

7. Sandhu B.K. and Paul S.P. Irritable bowel syndrome in children. Pathogenesis, diagnosis and evidence-based treatment. World J Gastroenterol. 2014, 20(20):6013-6023.

8. Sheykhzadeh P, Irritable Bowel Syndrome, Digestive Health Associates March 12, 2015.

9. Canavan $C$, West $J$ and Gard T. Review article: The economic impact of the irritable bowel syndrome. Aliment Pharmocol Ther. 2014; 40:10231034.

10. Wong R.K, Drossman D. A, Weinland S. R, and Morris C.B. Partner Burden in Irritable Bowel Syndrome. Clin Gastroenterol Hepatol. 2013; 11:151-55.

11. Mearin F, Lacy B.E, Chang L. Chey W. D \& Spiller R..Bowel disorder. Gastroenterology 2016; 150:1393-1407.

12. The American Institute of Stress. 2017.

http:/www.stress.org/holmes-rahe-stress-inventory. 23/9/2017

13. Longstreth, GF, Thompson, WG, Chey, WD, Houghton, LA, Mearin, F, Spiller RC. Functional Bowel Disorder. Gastroenterology, 2006, 130, 14801491.
14. Lacy E, Mearin F, Charg L, Chey L, Lemb J, Simren $M$, and Spiller R. Functional bowel syndrome. Gastroenterology 2016; 150:1393-1407.

15. Alhazmi A.H. Irritable bowel syndrome in secondary school male students in Al Jouf Province, north of Saudi Arabia, J Med Assoc., 2011; 61(11):1111-5.

16. EI-Fetoh, N.M.A., El-Mawgod M.M., Mohmmed N.A. and Alanazi E.O. Irritable Bowel Syndrome among Medical and Non-medical Northern Border University Students, Kingdom of Saudi Arabia: Across Sectional Study. Open Journal of Gastroenterology, 2016, 6, 188-195.

17. Zedan J, Comparative Study between the Prevalence of Irritable Bowel Syndrome in Hypertensive Patients and General Population in Tikrit. Tikrit Medical J. 2007; 13(2):156-160.

18. Adeniyi $O$, Irritable bowel syndrome in adolescents in Lagos. Pan African Medical JournalISSN 2017; 1937-8688.

19. Devanarayana N.M, Rajindrajith S.R, Pathmeswaran P.and Benninga M.A. Epidemiology of irritable bowel syndrome in children and adolescents in Asia.2015. Journal of Pediatric Gastroenterology and Nutrition 2015; 60: 792-8.

20. Zhu X, Chen W, Shen $Y$. A cross-sectional study of risk factors for irritable bowel syndrome in children 8-13 years of age in Suzhou, China. Gastroenterology Res. Pact. 2014; 2014:198461.

21. Chatila R, Merhi M, Hariri E, Sabbah N, and Deeb M. Irritable bowel syndrome: Prevalence, risk factors in adults Lebanese Population. BMC Gastroenterology. 2017:17:137.

22. Thakur E.R, Gurtman M.B, Keefer L, Brenner D.M, and Lacker J.M. Gender differences in irritable bowel syndrome. Neurogasteroenterol 2015; 27(10):1478-1486.

23 .Liu, Y., l., Yang, Y., He, Y., Wang, M., Chen, S. and Shukun, Y. (2014) A School-Based Study of Irritable Syndrome in Medical Students in Beijng, China: Prevalence and Some Related Factors Hindawi Publishing corporation. Gastroenterology Research and Practice, 2014, Article AD: 124261. 24. Al-bukhari I, Al-Malki K, kashkari M, Alrifai A, and Adnan M,. Prevalence and Factors Affecting of irritable bowel Syndrome among Medical Students at Tibah University. Clinical Medicine Research 2016; 5(1):1-5.

25. Costanian C., Tamim H., and Assaad S. "Prevalence and factors associated with irritable bowel syndrome among university students in Lebanon: Findings from a cross-sectional study." World Journal of Gastroenterology: WJG, 2015, 21.12: 3628

26. Almutairi $M$, AlQazlan $M$, Alshebromi A, Alawad M, and Zafar M. Prevalence of Irritable Bowel Syndrome and its Associated factors Among Medical Students. International journal of Medical Research and Health Sciences, 2017, 6(2):1-10.

27. Saito, Y.A., Petreson, G.M., Larson, J.J., Atkinson, E.J., Fridley, B.L., de Andrade, M. Familial Aggregation of Irritable Bowel Syndrome: A Family Case-Control Study. American Journal of 
Gastroenterology, 2010, 105, 833-84. 22. Basandra S., and Bajaj D. Epidemology of Dyspepsia and Irritable Bowel Syndrome in Medical Students of North India. J Clin. Diagn Res.2014; 8(12):13-6.

28. Panicker R., Arifhodzic N., Al Ahmad M. and Ali S.A. Association and symptom characteristics of irritable bowel syndrome among bronchial asthma patients in Kuwait. Ann Thorax. Med. 2010; 5(1):37-42. doi: 10.4103/1817-1737.58958.

29. Basandra S., and Bajaj D. Epidemology of Dyspepsia and Irritable Bowel Syndrome in Medical Students of North India. J Clin. Diagn Res.2014; 8(12):13-6.
30. Al-Ghamdi, S., AlQsamey, F., AlHamdan, A., Alnujaydi, A, AlRasheed, A., and Arneja, C. A study of impact and prevalence of irritable bowel syndrome among medical students. International Journal of Medicine and Medical Sciences. 2015; 7(9); 139-147.

31. Al-Turki, Y. A., Aljulii, M. Z., Al Murayshid, A., Al Omaish, H. R., Al Daghiri, K. S., Al Seleemi, A. Y. and Al Jerawi, A I. Prevalence of Irritable Bowel Syndrome among Students in King Saud University, Riyadh, Saudi Arabia. Middle East Journal of Family Medicine, 2011; 9(5). 5. 